Article

\title{
Evaluation of the Antimicrobial Activity of Cationic Peptides Loaded in Surface-Modified Nanoliposomes against Foodborne Bacteria
}

\author{
Stefania Cantor ${ }^{1}$, Lina Vargas ${ }^{1}$, Oscar E. Rojas A. ${ }^{1}$, Cristhian J. Yarce ${ }^{2}$ (D), \\ Constain H. Salamanca ${ }^{2, *(D)}$ and Jose Oñate-Garzón 1,2,*(D) \\ 1 Grupo de investigación en Química y Biotecnología (QUIBIO), Facultad de Ciencias Básicas, Universidad \\ Santiago de Cali, Calle 5 No. 62-00, Cali 760035, Colombia; estephye@hotmail.com (S.C.); \\ lina-vargas29@hotmail.com (L.V.); oerojas@usc.edu.co (O.E.R.A.) \\ 2 Laboratorio de Diseño y Formulación de Productos Químicos y Derivados, Departamento de Ciencias \\ Farmacéuticas, Facultad de Ciencias Naturales, Universidad Icesi, Calle 18 No. 122-135, Cali 760035, \\ Colombia; cjyarce@icesi.edu.co \\ * Correspondence: chsalamanca@icesi.edu.co (C.H.S.); jose.onate00@usc.edu.co (J.O.-G.). \\ Tel.: +57-2-5552334 (C.H.S.); +57-2-5183000 (J.O.-G.)
}

Received: 14 December 2018; Accepted: 2 February 2019; Published: 5 February 2019

\begin{abstract}
Bacteria are a common group of foodborne pathogens presenting public health issues with a large economic burden for the food industry. Our work focused on a solution to this problem by evaluating antibiotic activity against two bacteria (Listeria monocytogenes and Escherichia coli) of relevance in the field of foodstuffs. We used two approaches: (i) structural modification of the antimicrobial peptides and (ii) nano-vehiculisation of the modified peptides into polymer-coated liposomes. To achieve this, two antimicrobial peptides, herein named 'peptide $+2^{\prime}$ and 'peptide $+5^{\prime}$ were synthesised using the solid phase method. The physicochemical characterisation of the peptides was carried out using measurements of surface tension and dynamic light scattering. Additionally, nanoliposomes were elaborated by the ethanol injection method and coated with a cationic polymer (Eudragit E-100) through the layer-by-layer process. Liposome characterisation, in terms of size, polydispersity and zeta potential, was undertaken using dynamic light scattering. The results show that the degree of hydrophilic modification in the peptide leads to different characteristics of amphipathicity and subsequently to different physicochemical behaviour. On the other hand, antibacterial activity against both bacteria was slightly altered after modifying peptide sequence. Nonetheless, after the encapsulation of the peptides into polymer-coated nano-liposomes, the antibacterial activity increased approximately 2000-fold against that of L. monocytogenes.
\end{abstract}

Keywords: Cationic antimicrobial peptide; polymer-coated liposomes; foodborne pathogens

\section{Introduction}

Foodborne illnesses have significant impacts on global healthcare systems. There is a growing concern regarding foodborne bacterial pathogens; the World Health Organisation (WHO) estimates that, in 2010, foodborne illnesses affected 600 million people globally and caused 420,000 deaths [1]. To contribute to solving this public health problem, alternative antibiotics have emerged, such as antimicrobial peptides (AMPs); e.g., Nisin is an AMP widely used as an additive to foodstuffs and is the only bacteriocin approved by FDA and European Union (E234) [2]. AMPs are natural antimicrobial agents constituting the innate immune system, which mainly target anionic microbial membranes as consequence of peptide cationic charge, a result of the initial interaction between the peptide 
and the microbial membrane [3,4]. Subsequently, the hydrophobic amino acids are inserted into the hydrophobic core of the membrane, increasing the disorder of the phospholipids while the barrier membrane function is lost [3]. Thus, other peptide structural properties, such as hydrophobicity, amphipathicity and secondary structure, play a pivotal role to achieve insertion into the microbial membrane [5]. Indeed, such structural properties can modulate the physicochemical characteristics of both the peptide and the antimicrobial activity $[6,7]$.

Alyteserin-1c is an AMP comprising a 23 amino acid residue (net charge: +2 ) and was first isolated from norepinephrine-stimulated skin secretions from the midwife toad Alytes obstetricans [8]. Alyteserin-1c has shown antibacterial selectivity against Gram-negative bacteria, exhibiting a MIC of $25 \mu \mathrm{M}$ for E. coli. Furthermore, low hemolytic activity against human erythrocytes has been described [8,9]. Although AMPs are an alternative means for eliminating bacteria in foods, due to their biocompatibility, biodegradability, broad spectrum of activity and potent bactericidal properties, most have not been successfully applied to food preservation, since their susceptibility to enzymatic degradation limits their bioavailability [10]. Efforts to improve peptide stability against a range of environmental and chemical stresses have been developed, for instance vehiculisation using liposomes composed of membrane phospholipids exhibiting excellent biocompatibility [11-13]. However, such systems are thermodynamically unstable, resulting in aggregation phenomena by mechanisms such as flocculation and coalescence during storage that can lead to a burst release of the active agent [14]. Thus, the liposomal surface can be decorated with polymers to enhance its stability and functionality. Eudragit E- $100{ }^{\circledR}$ is a polymer widely used for enteric coating, categorised as nontoxic and nonirritant and is approved by the FDA Inactive Ingredients Guide (in their forms of oral capsules and tablets) [15]. It is therefore an inexpensive polymer with potential utility to the food industry for coating liposomes.

Recent studies with Nisin encapsulated into polymer coated-liposomes have shown that it exhibits an increased peptide stability and antimicrobial activity against foodborne pathogens. Niaz et al. [2] found that Nisin-loaded, multi-component colloidosomes have superior potential to control resistant foodborne pathogens when compared to free Nisin. Additionally, Nisin-loaded pectin or polygalacturonic acid-coated liposomes exhibited an enhanced efficiency against L. innocua $6 a$ when compared with free Nisin [16]. Thus far, there have been few studies examining the antimicrobial effect of AMPs encapsulated into coated liposomes [16-19] and the current knowledge of how the structural and physicochemical properties of peptide impacts their ability to be encapsulated into liposomes is limited.

The aim of this research was to design and synthesise a peptide (+5) from Alyteserin-1c (+2) by the replacement of hydrophobic amino acids by hydrophilic amino acids at the polar face of the helix, increasing both the amphipathicity and cationic charge while decreasing hydrophobicity. Analyses of the structural prediction and physicochemical properties of each peptide in solution were performed. Eudragit-coated liposomes were used as system encapsulating peptides, and the effect of the structural and physicochemical properties of the peptides on encapsulation and biological activity were reported. Susceptibility tests using encapsulated and free peptide were performed against foodborne bacteria.

\section{Results and Discussion}

\subsection{Peptides Design and Sequence Characteristics}

The peptide +2 (HOUSY4, code UniProt KB), constituting 23 residues, is Alyteserin-1c isolated from the amphibian Alytes obstetricans and has a sequence described by Conlon et al. [8]. Peptide +2 was selected as a template sequence due to both, its reduced positive net charge and the presence of hydrophobic amino acids in the polar face of the helix, in order to explore the effect of increasing charge and hydrophilicity in that helix face on the biological activity, encapsulation ability and physicochemical properties. Peptide +5 is a derivate of the peptide +2 , which has increased cationic properties as a result of the rational replacement of anionic and hydrophobic residues by hydrophilic and cationic residues at the polar face, shown in Table 1 (bold letters), following the Bordo and Argos 
suggestions [20] and maintaining similar structural properties after substitutions. The characteristics of both peptides are summarised in Table 1, including the hydrophobic character, amphipathicity, molecular weight and the net charge at $\mathrm{pH}$ 7.4. Peptide +5 had four substitutions (E4R, A8S, S12K and A18S). Furthermore, the substitution of hydrophobic alanine for hydrophilic serine at the polar face decreased its hydrophobicity from 0.461 (peptide +2 ) to 0.373 (peptide +5 ), whereas the hydrophobic moment was increased from 0.380 (peptide +2 ) to 0.434 (peptide +5 ) (Table 1). Evidently, altering one structural property will often result in significant changes to one or more of the other properties.

Table 1. Peptide sequences and properties.

\begin{tabular}{|c|c|c|c|c|c|c|c|}
\hline \multirow{2}{*}{ Name } & \multicolumn{3}{|c|}{ Sequence } & \multirow{2}{*}{ Q } & \multirow{2}{*}{$<\mathrm{H}>$} & \multirow{2}{*}{$<\mu \mathrm{H}>$} & \multirow{2}{*}{ MW } \\
\hline & 1 & 10 & 20 & & & & \\
\hline peptide +2 & \multicolumn{3}{|c|}{$\mathrm{H}_{2} \mathrm{~N}$ - GLKEIFKAGLGSLVKGIAAHVAS-COOH } & +2 & 0.461 & 0.38 & 2266.7 \\
\hline peptide +5 & \multicolumn{3}{|c|}{$\mathrm{H}_{2} \mathrm{~N}-$ GLKRIFKSGLGKLVKGISAHVAS-COOH } & +5 & 0.373 & 0.434 & 2366.9 \\
\hline
\end{tabular}

After the substitution of these residues, the modified peptides exhibited enhanced hydrophilicity in the polar face of the helix, whereas the hydrophobic face was unaltered (Figure 1B). At the first 18 amino acids of the sequence, the polar face consisted of 10 amino acids, of which 6 were conserved in the modified peptide (G1, K3, K7, G11 and K15). On the other hand, the hydrophobic face is constituted by 8 amino acids: one F, two I, three L and two G (Figure 1).
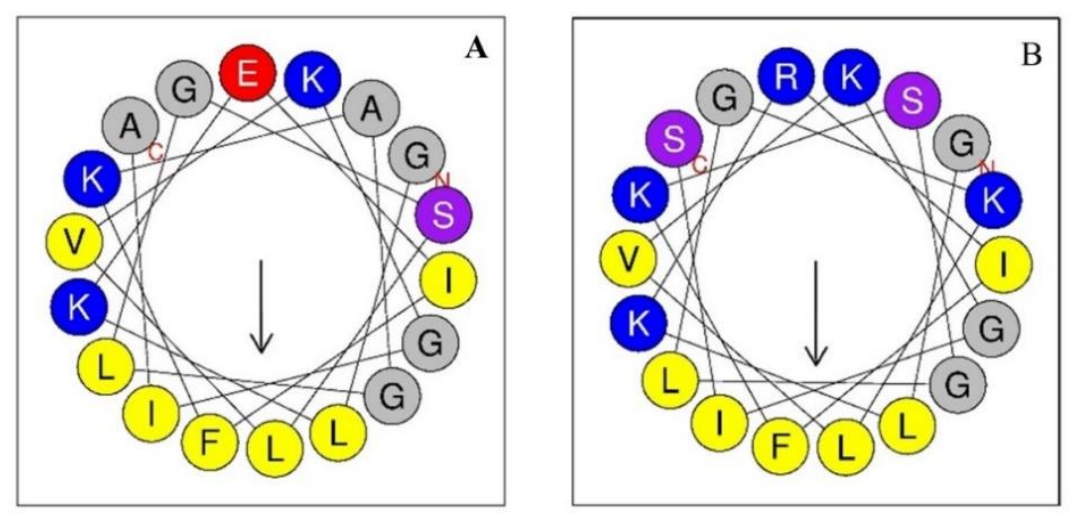

Figure 1. Wheel projections of the first 18 residues of the sequence of each peptide. (A) Alyteserin-1c peptide $(+2)$; (B) peptide +5 . The hydrophobic amino acids are yellow, and the charged amino acids are blue (net positive) or red (net negative). The polar amino acids are purple and those in-between are grey.

\subsection{Molecular Dynamic Simulation}

Comparing both models, peptide +5 and peptide +2 , after energy minimisation shows that the transition of each residue towards minimum energy was mainly in the side chain, without further geometric optimisation of the amine (-NH) and carboxyl (-COOH) functional groups. Each residue showed a spatial shift, which was calculated by analysing the distances $(\AA)$ between the last functional group of the side chain of each residue of the peptide +5 in comparison with peptide +2 , where the residue that showed the greatest displacement to achieve the zero-energy trend was Lys12, calculated by comparing the nitrogen $\mathrm{Z}$ atom at a distance of $1.49 \AA$ (Figure 2). A greater displacement tendency was evidenced after the energy minimisation of peptide sequence residues from Lys12 to Ser23, where displacements with distances between $0.97 \AA$ and $1.49 \AA$ were applied. 


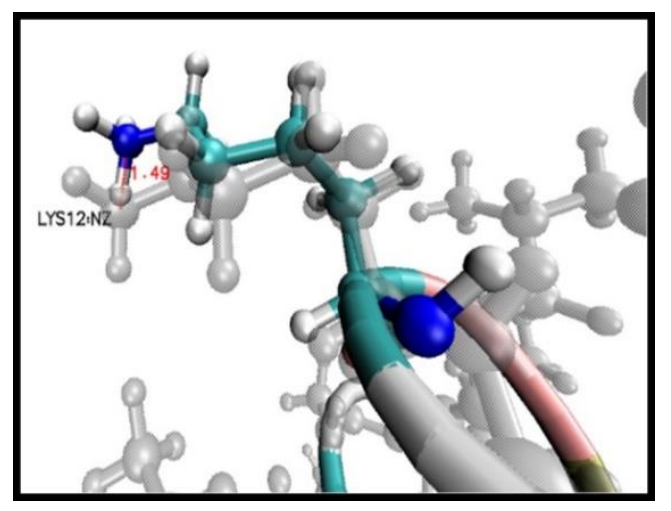

Figure 2. Atomic representation of the amino acid Lys12 in peptide +5 (color) compared with peptide +2 (gray); the nitrogen atom (blue color) is displaced $1.49 \AA$ to achieve energy minimisation.

The molecular dynamic (MD) simulation was performed using Periodic Boundary Conditions that are effective in eliminating surface interactions with water molecules and creating a more faithful representation of the in vivo environment [21]. The simulation time performed was sufficient to capture the long-time dynamics of a simple bimolecular system that required only the analysis of changes in the secondary structure and the determination of electrostatic interactions with the solvating model. After molecular dynamics, a NH-terminal sequence (GLKRIFKSGLGK) of peptide +5 interacting in a water box is responsible for the highest electrostatic interactions compared with the COOH-terminal region (Figure 3A). Arg4 is responsible for the electrostatic potential grid border and Lys15 exhibits electrostatic interaction only through its nitrogen atom, since these atoms in the side chain are more available for creating the electrostatic potential grid.

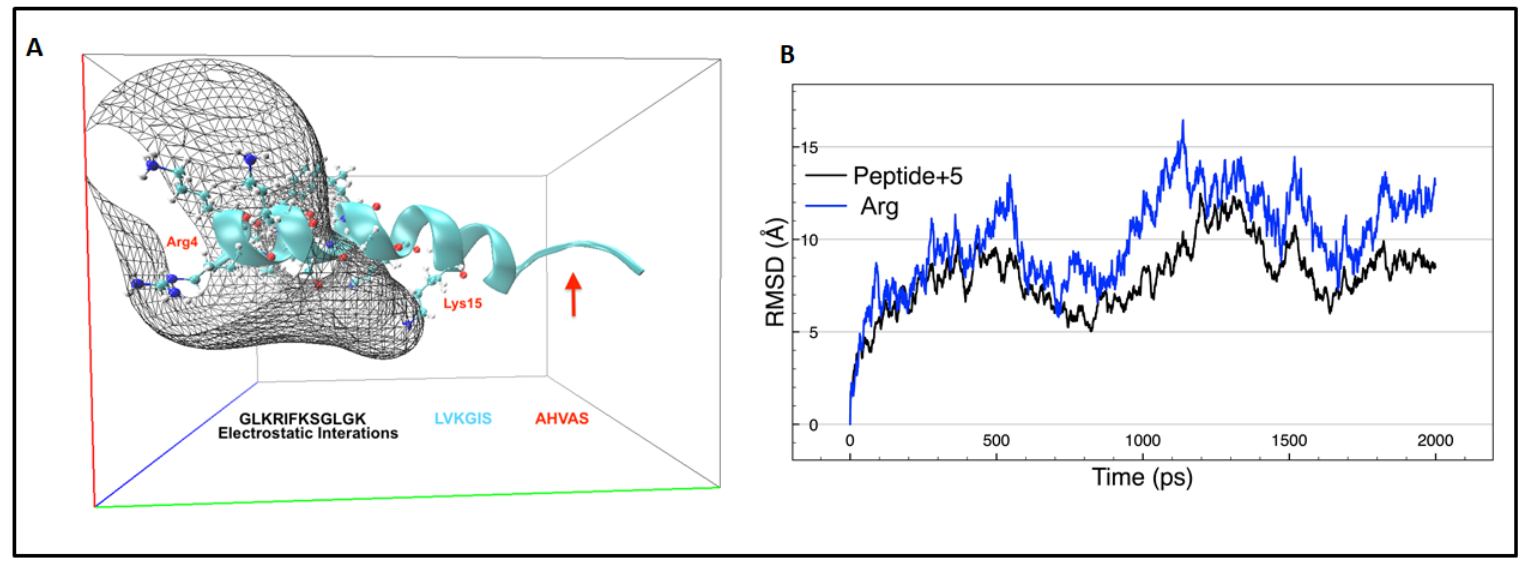

Figure 3. (A) Smoothed electrostatic potential grid model taken during $2000 \mathrm{ps}$ of molecular dynamics simulation and characterisation of the residues and sequence involved in the electrostatic interaction. (B) Root-mean-square deviation (RMSD) against time in picoseconds (ps); the black line represents the behaviour of all residues and the blue line represents the behaviour of only Arg4.

During the first 500 ps of molecular dynamics, the peptide +5 lost $\alpha$-helix structure at the amino acid sequence AHVAS (Figure 3A). The replacement of alanine 18 by serine appears to contribute to the loss of the $\alpha$-helix structure since alanine has the highest helix-forming propensity [22]. Special attention was required in the case of residue Arg4 because, throughout all molecular dynamic simulations, it showed high movement in its side chain (Figure 3B) owing to the reactivity of the guanidine group. This side chain plays a pivotal role in microbial membrane interaction since it can approach the heads of phosphatidylglycerol to a distance of $5 \AA$ [23]. Furthermore, arginine has the ability to internalise the peptides into the cells by crossing the membrane [24]. 


\subsection{Characterisation Physicochemical of Peptides in Aqueous Media}

The results of the surface tension and aggregation index with respect to the concentration of the peptides +2 and +5 are shown in Figure 4 .
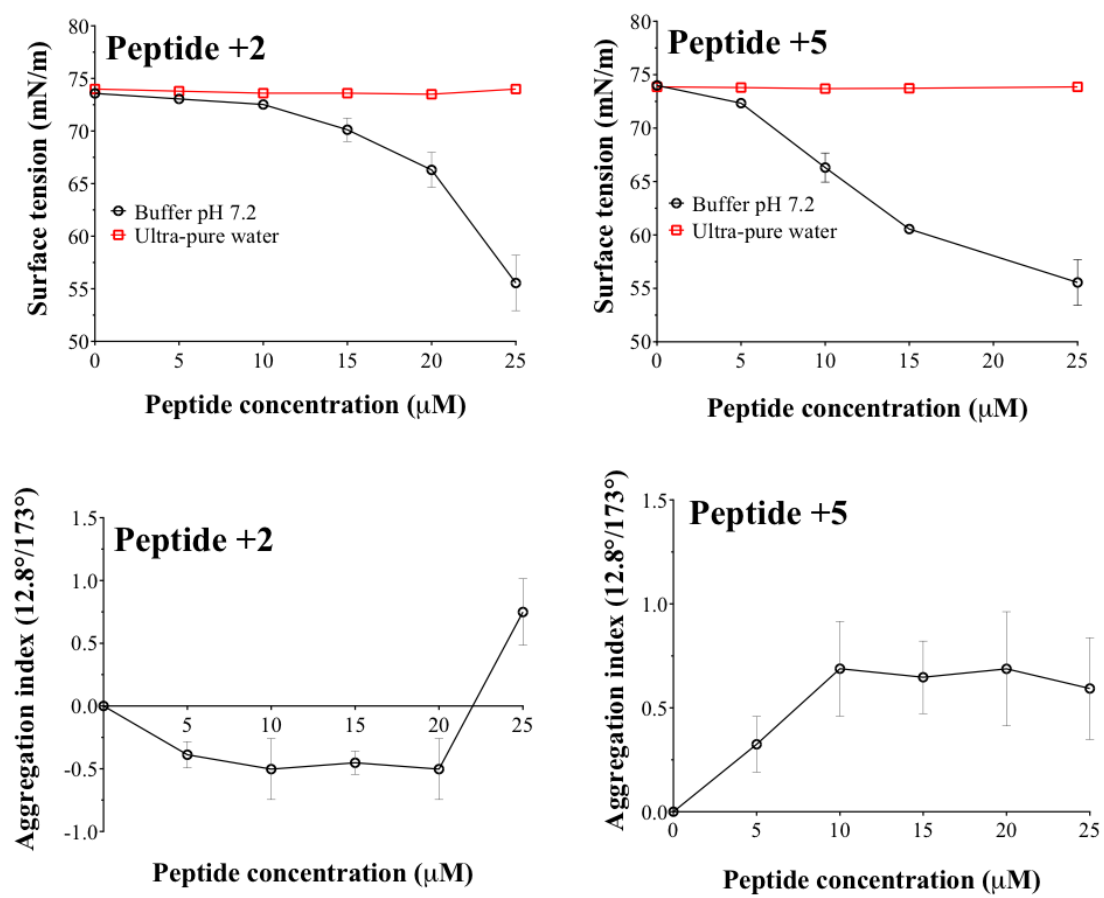

Figure 4. Changes in aggregation index and surface tension as a function of peptide concentration.

The results show a marked effect depending on both the medium (ultrapure water or phosphate buffer) and the degree of hydrophilicity of the peptide face. Regarding the medium, when the peptides are dissolved in ultra-pure water, it is observed that there are variations neither in surface tension nor in the aggregation index. This result is very interesting and leads us to propose two possible hypotheses. (i) When the peptides are in the water, these could be mostly adsorbed on the container surface and thus, the peptide amount dissolved in ultra-pure water is insufficient to give some response in regards to the methodologies employed. (ii) There is an effect provided by the hydrophilic character in the peptide face. This result can be explained by the hydrophilic character of both peptides like that, being in an aqueous medium (free ions), they tend to be completely solvated in the bulk of the system. On the contrary, when the peptides are in a phosphate buffer medium, the cationic counter ions (from the buffer) cause a charge shielding effect on the peptide face. This effect generates a change in the hydrophilic-hydrophobic character of the peptide structure, passing from a hydrophilic to an amphipathic structure and, thus, changing the thermodynamic behaviour similarly to a surfactant. Comparing the results of both peptides, it is observed that in the peptide +5 (more hydrophilic), changes in surface tension and aggregation index are achieved at lower concentrations $(5-10 \mu \mathrm{M})$ than with peptide $+2(20 \mu \mathrm{M})$. This result suggests that peptide +5 acquires a more amphipathic character than peptide +2 and that peptide +5 tends more to aggregation. These results are significant as it has been described that peptide or protein systems are biologically more active when they are in non-aggregated form $[25,26]$. These results are necessary to project the vehiculisation process within the liposomes, where the peptides could interact with the components forming the lamellar structure, affecting nano-formulation.

\subsection{Polymer-Coated Liposome Coated with Peptides}

The results of the DLS characterisation of the polymer-coated liposomes, both free and loaded with the peptides +2 and +5 , are shown in Figure 5 . 


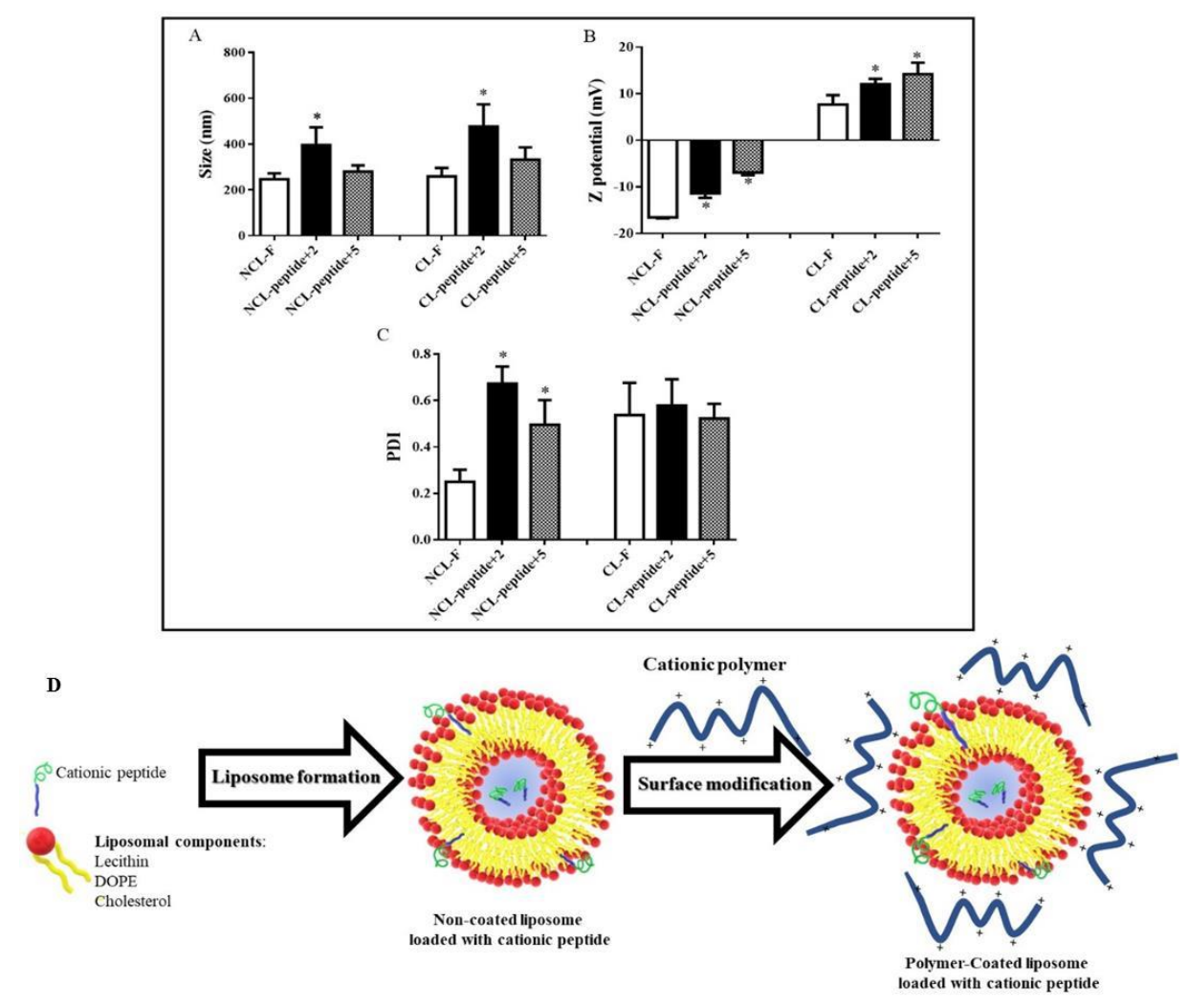

Figure 5. Mean values of (A) particle size, (B) Z-potential, (C) polydispersity index (PDI) and (D) scheme formation of liposomes loaded with cationic peptides +2 and +5 before (NCL) and after (CL) the coating process. Data are the average of at least three independent experiments \pm s.d. Error bars represents the standard deviation. * Significant difference $p<0.05$ to the NCL and CL without peptide (NCL-F and CL-F, respectively).

Figure 5A shows that the non-coated and unloaded peptide liposomes (NCL-F) have sizes around $235 \mathrm{~nm}$, however, when they are loaded with the peptides +2 (NCL-peptide +2 ) and +5 (NCL-peptide +5$)$, respectively, their sizes increase to almost twice their initial size, with a marked increase in polydispersity index (PDI) (Figure 5C) from low polydispersity (PDI <0.3) (NCL-F) to high polydispersity (PDI 0.5-0.7) (NCL-peptide +2 and +5 ). This result can be explained by considering several aspects: (i) the peptides are located inside the liposome in the internal aqueous compartment, (ii) the peptides are located on the liposomal surface, or (iii) the peptides are located on both sides. According to the zeta potential results (Figure 5B), such values tend to be negative due to the nature of the components used to form the liposomal structure (NCL-F). On the contrary, when the peptides are present, the zeta potential values become less negative, suggesting that some amount of cationic peptide could be interacting with the surface. Therefore, it can be determined that both peptides are located both inside the liposome and in the lamellar structure.

Conversely, the liposomal coating process shows changes in size, polydispersity and zeta potential. Size increases tend to be proportional both in the unfilled liposomes (CL-F) and in those loaded with peptides (CL-peptide +2 and +5 ). The polydispersity index increases in all cases, suggesting that the coating polymer adheres in different ways to the liposomal surface, leading to different size populations.

In relation to the zeta potential results, an inversion in the sign of the values from negative to positive (CL-F) is shown, suggesting that the coating polymer effectively adheres to the polymeric surfaces. The aforementioned result, which positive zeta potential is coherent if it is considered that the polymeric material used corresponds to a cationic salt derived from the Eudragit E-100 and, therefore, it could provide such a surface. Furthermore, as the charge on the peptide face increases, the 
zeta potential values become higher (CL-Peptide +2 and +5 ), thus reaffirming that the peptides are distributed both inside the liposome and in the lamellar structure (Figure 5D).

Conversely, it should be mentioned that although several methodologies were attempted to quantify the degree of encapsulation of the peptides within the nano-liposomes, such as dialysis, pressure-assisted ultrafiltration, ultrafiltration/centrifugation, but none were successful. This was because the ammonium salt present in the polymer derived from Eudragit E-100 interfered with the peptide quantification methodology (Bradford colorimetric method). To achieve such quantification, it would be necessary to employ a discriminative and sensitive methodology, such as mass spectrometry coupled to liquid chromatography with UV-Vis detector. However, the results nonetheless indirectly suggest the vehiculisation of the peptides in the liposomes but the peptide encapsulated fraction is now and interesting topic to be addressed in future works.

\subsection{Stability of Liposomes}

The results of the stability study of the non-coated liposome (NCL) and polymer-coated liposome (CL) showed that the liposome surfaces modified with the Eudragit E-100 polymer were more stable than the non-coated liposomes (Figure 6). This result is consistent with the electrostatic stablisation effect, which increases with the adsorption of the polymer on the liposome surface and forms a positive electrostatic film preventing liposomal aggregation and extending the limits of physical stability. This result is very interesting because it shows that coated liposomes can reach a high stabilisation. However, it is important to highlight that to give a greater significance to this result, it will be necessary to carry out new comparative studies against other types of cationic liposomes (no-coated), such as the glutathione disulfide liposomes, which have shown very interesting characteristics corresponding to low toxicity, bioability and adequate physico-chemical stability [27-29].

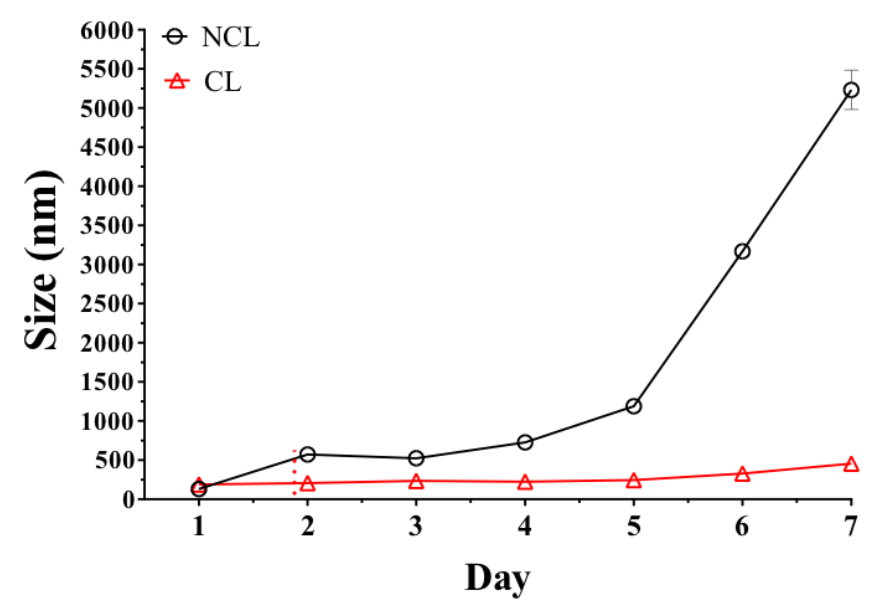

Figure 6. Evaluation of liposomal size change with time.

\subsection{Antimicrobial Activity}

Antibacterial activity against Gram-negative bacteria was determined, showing that peptide +2 exhibited increased activity, unlike peptide +5 , reaching a MIC value of $15.2 \mu \mathrm{M}$ for E. coli whereas peptide +5 exhibited a MIC of $62.5 \mu \mathrm{M}$. In Gram-negative bacteria, the self-promoted uptake pathway is a proposed mechanism that appears to be related with bacterial death, where the cationic peptide displaces divalent cations associated with lipopolysaccharides (LPS), destabilising the macromolecular complex and promoting the internalisation of the peptide to the inner membrane [30]. However, the reduced activity exhibited in peptide +5 could also be due to the impediment of crossing the outer Gram-negative membrane to reach the periplasmic space and inner membrane, as a consequence of reduced hydrophobicity when replacing Ala/Ser at the polar face [5]. Hydrophobicity is thus an important parameter for peptide antibacterial activity as it controls the extent to which the peptide can 
partition into the hydrophobic core of the membrane [3]. Furthermore, the loss of the helical structure in the $\mathrm{COOH}$-terminal region of peptide +5 (Figure $3 \mathrm{~A}$ ) affects its antibacterial activity, since the disruption of the helical structures can lead to a dramatic decrease in activity [5]. On the other hand, the encapsulation of peptides into NCL had no additional antimicrobial effect against $E$. coli, since these colloidal systems can be degraded by flocculation or coalescence processes [14]. Nonetheless, after coating the liposome with Eudragit polymer, the MIC was reduced, reaching values of 1.25 and $5 \mu \mathrm{M}$ for CL-peptide +2 and CL-peptide +5 , respectively, corresponding to an increase in antibacterial activity of the peptide +2 (peptide $+2 /$ CL-peptide +2 ) of approximately 12.5 times after being encapsulated into the liposomal formulation. These vehicles would avoid chemical degradation by bacterial proteases of the encapsulated peptides, and thus, their release onto the bacterial surface is favoured [31]. After the CL is anchored to the bacterial surface, Eudragit would be stripped of liposome and NCL is internalised in the cell by endocytosis (or phagocytosis), followed by the enzymatic digestion of the liposome in the intracellular compartment (endosome, phagosome or acidosome) [32], while the intact AMP is distributed over the bacterial membrane.

Conversely, increasing the hydrophilicity, charge and amphipathicity of the Alyteserin-1c peptide sequence resulted in a slight enhancement of antimicrobial activity in L. monocytogenes, with MIC values of 125 and $62.5 \mu \mathrm{M}$ for peptide +2 and +5 , respectively. The cationic charge has been widely associated with the antimicrobial activity of AMPs $[6,33,34]$ since the surface charge density of the membrane determines the magnitude of the electrostatic attraction (Coulombic) linking the positively charged molecules of the peptide to the negatively charged lipid membranes [35]. Thus, peptide +5 can be more strongly attracted by anionic groups positioned toward the outside of the cell wall than its analogue +2 , due to the presence of carboxyl groups of the muramyl peptides of peptidoglycan and the carboxyl and phosphate groups of teichoic acids located at Gram-positive external envelope [36]. Furthermore, bacterial anionic membranes constituted by anionic phospholipids [3] also contributes to the electrostatic attraction of cationic peptides.

After encapsulating peptides into NCLs, changes in the antibacterial activity against L. monocytogenes were not observed, a result consistent with previous observations in E. coli. However, after coating the NCL with polymer, an increase in activity against $L$. monocytogenes was observed, reducing the MIC to 0.06 and $0.04 \mu \mathrm{M}$ for CL-peptide +2 and CL-peptide +5 , respectively. It is important to mention that a part of this activity is provided by the blank coated liposome (CL-F), which exhibited a MIC of $3.9 \mu \mathrm{M}$, contrasting with that observed in E. coli where such formulation did not exhibit any antibacterial effect at the maximum tested concentration. Previous studies have shown that Eudragit shows a membrane-destabilising effect that is expressed as a perturbation of the membrane structure allowing the passage of water-soluble molecules, and also antiviral effects against the herpes simplex virus type 2 (HSV-2) [37]. Formulations with traditional antibiotics have also been described using Eudragit to increase their activity against $P$. aeruginosa with fluoroquinolone resistance [38]. Therefore, the encapsulation of the peptide +2 and the peptide +5 into CL increases the activity by 2083 (peptide+2/CL-peptide +2 ) and 1562 times (peptide $+5 /$ CL-peptide +5 ) against L. monocytogenes. Excluding the antibacterial contribution of CL-F, peptides +2 and +5 encapsulated into CL exhibited an enhanced activity of 65 and 97.5 times more than the unencapsulated peptides, respectively. In spite of that, the target of AMPs are the microbial membranes, they can be encapsulated and transported into membrane models without breaking them, since these models contain cholesterol and metastable zwitterionic phospholipids, which contribute to physical stability compared to a bacterial membrane $[39,40]$.

\section{Materials and Methods}

\subsection{Bacterial Strains and Chemicals}

L. monocytogenes ATCCbaa751 and E. coli ATCC25922, were obtained from the American Type Culture Collection (ATCC; Rockville, MD, USA). NovaPEG Rink Amida resin, Fmoc-protected amino 
acids, 2-(1H-benzotriazole-1-yl)-1,1,3,3-tetramethyluronium tetrafluoro-borate (TBTU), Piperidine, N,N-Diisopropylethylamine (DIEA), Ninhydrin, Dimethylformamide (DMF), Trifluoroacetic acid (TFA), 1,2-Ethanedithiol (EDT), Triisopropylsilane (TIS) and Mueller Hinton Broth (MHB) were purchased in Merck (Darmstadt, Germany). Cholesterol, Epikuron $200^{\circledR}$ and dioleoyl-phosphatidyl-ethanolamine (DOPE) were obtained from Avanti Polar Lipids (Alabaster, Alabama, USA). Eudragit ${ }^{\circledR}$ E-100 was purchased in Evonik (Darmstadt, Germany). Ampicillin (Fersinsa Gb) was supplied by Tecnoquímicas S.A. (Cali, Colombia) and Gentamicin solution (GENFAR ${ }^{\circledR}$, Cali, Colombia) was purchased from a local pharmacy. The datasets used and materials using during this study are available from the corresponding author on reasonable request.

\subsection{Peptide Design}

A sequence of the helical template peptide Alyteserin-1c (charge +2 , PDB code 2L5R), comprising 23 amino acid residues, was obtained from Conlon et al., [8]. Four amino acid substitutions were introduced in the polar face of amphiphilic helix into the wild-type (+2) sequence, following the suggestion of Bordo and Argos [20], in order to generate an analogue peptide (+5). The net charge of each peptide after residue substitution was calculated as the addition of the basic residues. Peptide hydrophobicity $\langle\mathrm{H}\rangle$, defined as the mean hydrophobicity value from all residues within a peptide according to a standard scale [41], and the hydrophobic moment $\langle\mu \mathrm{H}\rangle$, a quantitative measure of the amphipathicity defined as the vectorial sum of individual amino acid hydrophobicity vectors normalised to an ideal helix [42], were calculated using Heliquest software (http:/ / heliquest.ipmc. cnrs.fr/) (access on 6th march 2018). The structure prediction of peptide +5 was performed using a homology-based modelling procedure, where the amino acid sequence of Alyteserin-1c was the template for the amino acid substitutions, and side-chain modeling was carried out using DeepView Swiss-PdbViewer software (http:/ /www.expasy.org/spdbv/) (access on 25th may 2018).

\subsection{Peptide Synthesis}

The syntheses of Alyteserin-1c and its analogue were performed by solid phase methodology using NovaPEG Rink Amida resin and microwaves for coupling. After swelling, deprotection and washing of the quantified resin, a solution of activators (TBTU and DIEA) was mixed with Fmoc-protected amino acids. This mixture was irradiated with microwaves and washed with $20 \%$ piperidine in DMF for Fmoc deprotection. Deprotection and coupling were repeated with sufficient Fmoc-protected amino acids to obtain a peptide-resin complex. After each coupling step, the Kaiser test was used in order to confirm completeness of the coupling. Subsequently, the resin was washed twice successively with ether and was dried at $37^{\circ} \mathrm{C}$. Peptide was cleaved from the resin by treatment with Method 2 (94\% TFA/2.5\% water $/ 2.5 \%$ EDT/TIS 1\%) for $3 \mathrm{~h}$ under shaking conditions at room temperature, then dried and precipitated with cold ethyl ether. The ethyl ether was removed by centrifugation at $5000 \mathrm{rpm}$. Following this, peptides with 95\% purity were obtained by reverse phase, high-resolution liquid chromatography using a semi-preparative Chromolith ${ }^{\circledR} \mathrm{RP}-18 \mathrm{e}$ column and applying a mixture of: (A) $\mathrm{H}_{2} \mathrm{O}$ with $0.05 \%$ TFA $(v / v)$ and (B) acetonitrile containing $0.05 \%$ TFA $(v / v)$ as the mobile phase. For the elution of peptides, a programmed gradient of 70 min with $0 \times 50 \% \mathrm{~B}$ at $1 \mathrm{~mL} \times \mathrm{min}^{-1}$ and detection at $220 \mathrm{~nm}$ was used. The purity was verified using MALDI-TOF mass spectrometry (Bruker Daltonics, Bremen, Germany; MALDI Biotyper).

\subsection{Molecular Dynamic Simulation}

Electrostatic interaction potential was calculated using periodic boundary conditions (PBCs) and Particle Mesh Ewald (PME) methods in explicit solvent [43]. A TIP3 implicit water model simulation [44] with a $5 \AA$ rigid cubic cell was used to measure from the atom with the largest coordinate in every direction, (Vector 1: $31 \AA$, Vector 2: $44 \AA$ and Vector 3: $26 \AA$ ). A total of 2472 atoms were inserted, corresponding to 824 water molecules, with a final confirmation of: 2832 atoms, 2009 chemical bonds, 1485 angles, 950 dihedral angles, 2665 rigid bonds and 991 hydrogen groups. 
The structure (PDB file) and coordinates (PSF file) for Alyteserin-1c (2L5R) used for mutation were generated from topologies and initial force field parameters obtained from the Protein Data Bank (RCSB). The initial orientation was attained with Swiss.pdb Viewer. CHARMM force fields [21] were used throughout. To include long range electrostatic interactions in the simulations, the particle mesh Ewald method for periodic systems was used [43], since it creates a 3D grid over which the charge is distributed. The grid size was configured to $1 \AA$. The energy of the Peptide model was minimised every 100 steps with a $12 \AA$ cutoff. The MD simulation visualisation file was set to 250 steps per visualisation. The simulation time was 2000 ps with 2 fs per step (1000000 steps). Temperature and pressure were $310 \mathrm{~K}$ and $1 \mathrm{~atm}$, respectively, achieving an isobaric-isothermal ensemble. Visual Molecular Dynamics (VMD1.9.3, for visualisation) and the Scalable Molecular Dynamic (NAMD2.12) simulation software were used [45].

\subsection{Physicochemical Characterisation of the Peptide in Aqueous Media}

\subsubsection{Surface Tension Measurements}

Surface tension measurements of the peptides were carried out using a contact angle meter (OCA15EC Dataphysics Instruments, Filderstadt, Germany) with a software driver (version 4.5.14 SCA22), where the data capture was recorded using an IDS video camera. For this, the pendant-drop method $[46,47]$ was performed in triplicate, where peptide concentrations between 0 and $50 \mu \mathrm{M}$ were prepared with ultrapure water and phosphate buffer saline pH 7.2 (PBS, $138 \mathrm{mM} \mathrm{NaCl}, 3 \mathrm{mM} \mathrm{KCl}, 1.5$ $\mathrm{mM} \mathrm{NaH}_{2} \mathrm{PO}_{4}, 8.1 \mathrm{mM} \mathrm{Na}_{2} \mathrm{HPO}_{4}$ ).

\subsubsection{Aggregation Index Measurements}

The samples of peptides +2 and +5 were prepared in serial concentrations between 0 and $50 \mu \mathrm{M}$ in PBS buffer $\mathrm{pH} 7.2$ at $138 \mathrm{mM}$ of ionic strength. An aliquot was analysed immediately after preparation. Dual angle DLS measurements $\left(173^{\circ}\right.$ and $\left.13^{\circ}\right)$ of automatic duration were carried out using a Zetasizer Nano ZSP (Malvern Instruments, Worcestershire, United Kingdom). The Aggregation Index is a parameter based on the mean z-average size measured for the two angles of scattering according to the equation:

$$
\text { Aggregation index }=\left[\frac{Z_{f w d}}{Z_{b k d}}-1\right]
$$

where, $Z_{f w d}$ is the average particle size detected by forward scatter optics at $13^{\circ}$. Trace amounts of aggregate are often highly useful for the enhanced detection of large protein aggregates, whereas $Z_{b k d}$ is the particle size average at a detection angle of $173^{\circ}$ (non-invasive back-scatter).

\subsection{Polymer-Coated Liposome Coated with Peptides}

\subsubsection{Preparation of Liposomes Loaded with Peptide}

Liposomes were developed using the ethanol injection method. The liposomes were prepared on the basis of a sequential process defined in several steps. Step 1, (preparation of organic phase): ethanolic solutions of Epikuron $200^{\mathrm{TM}}(1.3 \mathrm{mg} / \mathrm{mL})$, cholesterol $(0.64 \mathrm{mg} / \mathrm{mL})$ and DOPE $(1.23 \mathrm{mg} / \mathrm{mL})$ were prepared, from which volumes of $42.3,42.4$, and $15.3 \mu \mathrm{L}$ were taken, respectively, to obtain $100 \mu \mathrm{L}$ of the lipid mixture and settled in a $200 \mu \mathrm{L}$ eppendorf PCR chemically inert, prime virgin polypropylene (PP) tube (Eppendorf AG, Hamburg, Germany). Step 2 (phase mixture): $100 \mu \mathrm{L}$ of organic phase was slowly injected to $100 \mu \mathrm{L}$ of aqueous phase composed of peptides at a concentration of $125 \mu \mathrm{M}$ dissolved in phosphate buffered saline (PBS, $138 \mathrm{mM} \mathrm{NaCl}, 3 \mathrm{mM} \mathrm{KCl}$, $1.5 \mathrm{mM} \mathrm{NaH}_{2} \mathrm{PO}_{4}, 8.1 \mathrm{mM} \mathrm{Na}_{2} \mathrm{HPO}_{4}, \mathrm{pH}$ 7.2) which were stirred (in vortex) for $1 \mathrm{~min}$ and left under 'aging' by $10 \mathrm{~min}$. Step 3 (formation of liposomes): The resulting mixture between the organic and the aqueous phases were diluted in $300 \mu \mathrm{L}$ of the respective aqueous media. Step 4 (liposome purification): The diluted mixture was centrifuged at 10,000 rpm in a micro-centrifuge Hettich RCF 10,538 (Andreas 
Hettich GmbH and Co.KG, Tuttlingen, Germany) for 6 min, using $500 \mu \mathrm{L}$ centrifugal filters tubes (VWR, Radnor, PA, USA) with a pore size of $30 \mathrm{kDa}$. Subsequently, the fractions of purified liposomes (supernatant of filtering process) were extracted, resuspended and adjusted to a volume of $1000 \mu \mathrm{L}$ in the respective aqueous media.

\subsubsection{Liposome Surface Modification}

An aqueous solution of Eudragit ${ }^{\circledR}$ E-100 $(0.7 \%$ w/v) adjusted to $\mathrm{pH} 4.0$ with $0.1 \mathrm{M} \mathrm{HCl}$, was added to liposomal dispersion loaded with peptide (previously elaborated), at a ratio of 1:1 and at a rate of $50 \mu \mathrm{L} / \mathrm{min}$. Subsequently, the mixture was left under constant magnetic stirring at $300 \mathrm{rpm}$ for $8 \mathrm{~h}$ in a polypropylene closed vessel. Finally, it was centrifuged at 10,000 rpm for $2 \mathrm{~min}$, using the centrifugal filters with $30 \mathrm{kDa}$ cut-off. This surface modification technique was previously reported and it is called layer-by-layer coating process [48].

\subsubsection{Physicochemical Characterisation of Liposomes}

Particle size and zeta potential were determined using a Zetasizer nano ZSP (Malvern Instrument, Worcestershire, United Kingdom) with a red He/Ne laser $(633 \mathrm{~nm})$. Particle size was measured using dynamic light scattering (DLS) with an angle scattering of $173^{\circ}$ at $25^{\circ} \mathrm{C}$, in a quartz flow cell (ZEN0023), whereas zeta potential was measured using a disposable folded capillary cell (DTS1070). This instrument reports particle size as the mean particle diameter (z-average), and PDI ranging from 0 (monodisperse) to 1 (very broad distribution). All measurements were performed in triplicate after an appropriate dilution $(5: 5000, v / v)$ of the liposome suspension in ultra-pure water and were reported as the mean and standard deviation of measurements made from freshly prepared liposomal dispersions.

\subsubsection{Stability of Liposomes}

The stability of the coated and non-coated liposomes was assessed using a stability chamber at $40 \pm 1{ }^{\circ} \mathrm{C}$, where the change in liposomal size was evaluated for 7 days in triplicate.

\subsection{Antimicrobial Activity}

Microbial susceptibility tests were performed according to clinical and laboratory standards institute (CLSI) standard methods [49]. Bacteria were inoculated in MHB and incubated overnight at $37^{\circ} \mathrm{C}$. The culture was then diluted in $\mathrm{MHB}$ until an $\mathrm{OD}_{625}$ of 0.1 was reached (approximately $1 \times 10^{8} \mathrm{CFU} / \mathrm{mL}$ ) and additional incubation was continued for $30 \mathrm{~min}$. Such cultures were diluted by a factor of 1:200. Subsequently, $90 \mu \mathrm{L}$ of bacterial culture was incubated for 18-20 h into 96-well plates at $37^{\circ} \mathrm{C}$ with $10 \mu \mathrm{L}$ of free or encapsulated peptide until a final inoculum of approximately $5 \times 10^{5}$ $\mathrm{CFU} / \mathrm{mL}$ was reached. Treatments were applied at different serial concentrations ranging from 15.2 to $250 \mu \mathrm{M}$. As negative control, PBS was used, and for positive control Gentamicin/ampicillin were used for Gram-negative and Gram-positive bacteria, respectively. After incubation, the minimum inhibitory concentration (MIC) was determined by visual analysis.

\subsection{Statistical Analysis}

Biological and physicochemical assays were performed in triplicate. After confirming the assumptions of normality and variance homogeneity, the data were analysed using ANOVA and Tukey's multiple comparisons method to determine if there are significant differences between the means obtained, using a significance level of $p<0.05$. All analyses were performed using the Statgraphics Centurion XVI software (StatPoint Technologies Inc, Warrenton, Va, EE. UU.).

\section{Conclusion}

The purpose of the replacement of amino acids in this study was to develop an approach to an ideal amphipathic $\alpha$-helix with hydrophobic residues at one side of the helix and cationic/hydrophilic 
residues at the other side. This involved the introduction of hydrophilic amino acids at the polar face. We found that hydrophobicity/amphipathicity and charge have effects on the physicochemical properties of both the peptides and the liposomes encapsulating them. Additionally, by substituting amino acids, an increase of specificity toward Gram-positive bacteria can be achieved. On the other hand, the encapsulation of the peptide Alyteserin-1c into polymer-coated liposomes increased the antibacterial activity significantly (2083 times) against $L$. monocytogenes and modestly (12.5 times) against E. coli, in comparison with the unencapsulated peptide. Both bacterial strains present a serious risk when consumed in contaminated food, since they are extremely virulent in humans. L. monocytogenes has particularly remarkable resistance to the usually deleterious effects of freezing, drying and heating [50]. Therefore, the application of funtionalised liposomes coated with food-safe polymers for the encapsulation of small traces of biocompatible non-traditional antibiotics results in a potent bactericidal formulation and provides a promising solution to mitigate the bacterial resistance problem toward food storage conditions, avoiding the spread of infections by foodborne pathogens.

Author Contributions: J.-O.G. designed antimicrobial peptides and conducted the nano-encapsulation of peptides and antibacterial activities. C.H.S. designed the formulations of colloidal suspensions, the physicochemical measurements and analysed all obtained results. L.V. synthesised, purified and characterised both peptides. C.J.Y. determined the physicochemical properties of the peptides and contributed in the liposomal formulation. O.E.R.A. developed molecular dynamic analysis and S.C. executed pendant drop methodology, nano-encapsulation, physicochemical characterisation and antibacterial activity of the peptides before and after encapsulation. J.-O.G. and C.H.S. have equally contributed to this work and to the preparation of the manuscript.

Funding: This research was funded by Universidad Santiago de Cali, grant number DGI-COCEIN No 512-621116-A30 and Icesi University for the internal grant numbers CA041368 and CA041369.

Acknowledgments: J.-O.G. thanks to COLCIENCIAS by the Post-Doctoral fellowship and Icesi University for allowing me to carry out the postdoctoral stay in the Laboratory of Design and Formulation of Chemical Products. Also, we thank Universidad Santiago de Cali for the financial support.

Conflicts of Interest: The authors declare that they have no competing interests.

\section{Abbreviations}

$\begin{array}{ll}\text { AMP } & \text { Antimicrobial Peptide } \\ \text { FDA } & \text { Food and Drug Administration } \\ \text { MIC } & \text { Minimal Inhibition Concentration } \\ \text { Lys } & \text { Lysine } \\ \text { Ser } & \text { Serine } \\ \text { Arg } & \text { Arginine } \\ \text { Ala } & \text { Alanine } \\ \text { MD } & \text { Molecular Dynamic } \\ \text { RMSD } & \text { Root Mean Square Deviation } \\ \text { PDI } & \text { Polydispersity Index } \\ \text { NCL } & \text { non-coated liposomes } \\ \text { CL } & \text { coated liposomes } \\ \text { LPS } & \text { lipopolysaccharide } \\ \text { TBTU } & \text { 2-(1H-benzotriazole-1-yl)-1,1,3,3-tetramethyluronium tetrafluoro-borate } \\ \text { DIEA } & \text { N,N-Diisopropylethylamine } \\ \text { DMF } & \text { Dimethylformamide } \\ \text { TFA } & \text { Trifluoroacetic acid } \\ \text { EDT } & \text { 1,2-Ethanedithiol } \\ \text { TIS } & \text { Triisopropylsilane } \\ \text { MHB } & \text { Mueller Hinton Broth } \\ \text { DOPE } & \text { dioleoyl-phosphatidyl-ethanolamine } \\ \text { PBCs } & \text { Periodic Boundary Conditions } \\ \text { PME } & \text { Particle Mesh Ewald }\end{array}$




\section{References}

1. WHO. Estimates of the Global Burden of Foodborne Diseases; WHO: Geneva, Switzerland, 2015.

2. Niaz, T.; Shabbir, S.; Noor, T.; Abbasi, R.; Raza, Z.A.; Imran, M. Polyelectrolyte multicomponent colloidosomes loaded with nisin $\mathrm{Z}$ for enhanced antimicrobial activity against foodborne resistant pathogens. Front. Microbiol. 2018, 8, 2700. [CrossRef] [PubMed]

3. Teixeira, V.; Feio, M.J.; Bastos, M. Role of lipids in the interaction of antimicrobial peptides with membranes. Prog. Lipid. Res. 2012, 51, 149-177. [CrossRef] [PubMed]

4. Oñate-Garzón, J.; Ausili, A.; Manrique-Moreno, M.; Torrecillas, A.; Aranda, F.J.; Patiño, E.; Gomez-Fernández, J.C. The increase in positively charged residues in cecropin D-like Galleria mellonella favors its interaction with membrane models that imitate bacterial membranes. Arch. Biochem. Biophys. 2017, 629, 54-62. [CrossRef] [PubMed]

5. Lee, T.H.; Hall, K.N.; Aguilar, M.I. Antimicrobial Peptide Structure and Mechanism of Action: A Focus on the Role of Membrane Structure. Curr. Top. Med. Chem. 2016, 16, 25-39. [CrossRef] [PubMed]

6. Giangaspero, A.; Sandri, L.; Tossi, A. Amphipathic alpha helical antimicrobial peptides. Eur. J. Biochem. 2001, 268, 5589-5600. [CrossRef] [PubMed]

7. Torrent, M.; Andreu, D.; Nogués, V.M.; Boix, E. Connecting peptide physicochemical and antimicrobial properties by a rational prediction model. PLoS ONE 2011, 6, e16968. [CrossRef] [PubMed]

8. Conlon, J.M.; Demandt, A.; Nielsen, P.F.; Leprince, J.; Vaudry, H.; Woodhams, D.C. The alyteserins: Two families of antimicrobial peptides from the skin secretions of the midwife toad Alytes obstetricans (Alytidae). Peptides 2009, 30, 1069-1073. [CrossRef] [PubMed]

9. Conlon, J.M.; Ahmed, E.; Pal, T.; Sonnevend, A. Potent and rapid bactericidal action of alyteserin-1c and its [E4K] analog against multidrug-resistant strains of Acinetobacter baumannii. Peptides 2010, 31, 1806-1810. [CrossRef] [PubMed]

10. Mojsoska, B.; Jenssen, H. Peptides and Peptidomimetics for Antimicrobial Drug Design. Pharmaceuticals 2015, 8, 366-415. [CrossRef] [PubMed]

11. Mosquera, M.; Giménez, B.; Da Silva, I.M.; Boelter, J.F.; Montero, P.; Gómez-Guillén, M.C.; Brandelli, A. Nanoencapsulation of an active peptidic fraction from sea bream scales collagen. Food Chem. 2014, 156, 144-150. [CrossRef] [PubMed]

12. Ron-Doitch, S.; Sawodny, B.; Kühbacher, A.; David, M.M.N.; Samanta, A.; Phopase, J.; Burger-Kentischer, A.; Griffith, M.; Golomb, G.; Rupp, S. Reduced cytotoxicity and enhanced bioactivity of cationic antimicrobial peptides liposomes in cell cultures and 3D epidermis model against HSV. J. Control. Release 2016, 229, 163-171. [CrossRef] [PubMed]

13. Alipour, M.; Halwani, M.; Omri, A.; Suntres, Z.E. Antimicrobial effectiveness of liposomal polymyxin B against resistant Gram-negative bacterial strains. Int. J. Pharm. 2008, 355, 293-298. [CrossRef] [PubMed]

14. Liu, W.; Liu, W.; Ye, A.; Peng, S.; Wei, F.; Liu, C.; Han, J. Environmental stress stability of microencapsules based on liposomes decorated with chitosan and sodium alginate. Food Chem. 2016, 196, 396-404. [CrossRef] [PubMed]

15. Kadian, S.S.; Harikumar, S.L. Eudragit and its Pharmaceutical Significance. Eudragit Pharm. Signif. 2009.

16. Lopes, N.A.; Pinilla, C.M.B.; Brandelli, A. Pectin and polygalacturonic acid-coated liposomes as novel delivery system for nisin: Preparation, characterization and release behavior. Food Hydrocoll. 2017, 70, 1-7. [CrossRef]

17. Gomaa, A.I.; Martinent, C.; Hammami, R.; Fliss, I.; Subirade, M. Dual Coating of Liposomes as Encapsulating Matrix of Antimicrobial Peptides: Development and Characterization. Front. Chem. 2017, 5, 103. [CrossRef] [PubMed]

18. Pu, C.; Tang, W. A chitosan-coated liposome encapsulating antibacterial peptide, Apep10: Characterisation, triggered-release effects and antilisterial activity in thaw water of frozen chicken. Food Funct. 2016, 7, 4310-4322. [CrossRef]

19. Da Silva, I.M.; Boelter, J.F.; Da Silveira, N.P.; Brandelli, A. Phosphatidylcholine nanovesicles coated with chitosan or chondroitin sulfate as novel devices for bacteriocin delivery. J. Nanopart. Res. 2014, 16, 2479. [CrossRef]

20. Bordo, D.; Argos, P. Suggestions for "safe" residue substitutions in site-directed mutagenesis. J. Mol. Biol. 1991, 217, 721-729. [CrossRef] 
21. MacKerell, A.D.; Bashford, D.; Bellott, M.; Dunbrack, R.L.; Evanseck, J.D.; Field, M.J.; Fischer, S.; Gao, J.; Guo, H.; Ha, S.; et al. All-Atom Empirical Potential for Molecular Modeling and Dynamics Studies of Proteins ${ }^{\dagger}$. J. Phys. Chem. B 1998, 102, 3586-3616. [CrossRef]

22. Alías, M.; Ayuso-Tejedor, S.; Fernández-Recio, J.; Cativiela, C.; Sancho, J. Helix propensities of conformationally restricted amino acids. Non-natural substitutes for helix breaking proline and helix forming alanine. Org. Biomol. Chem. 2010, 8, 788-792. [CrossRef] [PubMed]

23. Wang, G. Determination of solution structure and lipid micelle location of an engineered membrane peptide by using one NMR experiment and one sample. Biochim. Biophys. Acta 2007, 1768, 3271-3281. [CrossRef] [PubMed]

24. Mitchell, D.J.; Kim, D.T.; Steinman, L.; Fathman, C.G.; Rothbard, J.B. Polyarginine enters cells more efficiently than other polycationic homopolymers. J. Pept. Res. 2000, 56, 318-325. [CrossRef]

25. Lee, D.L.; Mant, C.T.; Hodges, R.S. A novel method to measure self-association of small amphipathic molecules: Temperature profiling in reversed-phase chromatography. J. Biol. Chem. 2003, 278, 22918-22927. [CrossRef] [PubMed]

26. Chen, Y.; Mant, C.T.; Farmer, S.W.; Hancock, R.E.; Vasil, M.L.; Hodges, R.S. Rational design of alpha-helical antimicrobial peptides with enhanced activities and specificity/therapeutic index. J. Biol. Chem. 2005, 280, 12316-12329. [CrossRef] [PubMed]

27. Sadhu, S.S.; Wang, S.; Dachineni, R.; Averineni, R.K.; Yang, Y.; Yin, H.; Bhat, G.J.; Guan, X. In Vitro and In Vivo Tumor Growth Inhibition by Glutathione Disulfide Liposomes. Cancer Growth Metastasis 2017. [CrossRef]

28. Goldenbogen, B.; Brodersen, N.; Gramatica, A.; Loew, M.; Liebscher, J.; Herrmann, A.; Egger, H.; Budde, B.; Arbuzova, A. Reduction-sensitive liposomes from a multifunctional lipid conjugate and natural phospholipids: Reduction and release kinetics and cellular uptake. Langmuir 2011, 27, 10820-10829. [CrossRef] [PubMed]

29. Sadhu, S.S.; Xie, J.; Zhang, H.; Perumal, O.; Guan, X. Glutathione disulfide liposomes-A research tool for the study of glutathione disulfide associated functions and dysfunctions. Biochem. Biophys. Rep. 2016, 7, 225-229. [CrossRef]

30. Hancock, R.E. Peptide antibiotics. Lancet 1997, 349, 418-422. [CrossRef]

31. Gregoriadis, G. Liposome technology, Vol II Entrapment of drugs and other materials into liposomes [Internet]. Third edit. Vol. I. Informa Healthcare USA Inc. 1984. Available online: http:/ / www.crcnetbase. com.ezlibproxy1.ntu.edu.sg/isbn/978-0-8493-8828-6 (accessed on 20 January 2019).

32. Daraee, H.; Etemadi, A.; Kouhi, M.; Alimirzalu, S.; Akbarzadeh, A. Application of liposomes in medicine and drug delivery. Artif. Cells Nanomed. Biotechnol. 2016, 44, 381-391. [CrossRef]

33. Oñate-Garzón, J.; Manrique-Moreno, M.; Trier, S.; Leidy, C.; Torres, R.; Patiño, E. Antimicrobial activity and interactions of cationic peptides derived from Galleria mellonella cecropin D-like peptide with model membranes. J. Antibiot. 2017, 70, 238-245. [PubMed]

34. Jiang, Z.; Vasil, A.I.; Hale, J.D.; Hancock, R.E.; Vasil, M.L.; Hodges, R.S. Effects of net charge and the number of positively charged residues on the biological activity of amphipathic alpha-helical cationic antimicrobial peptides. Biopolymers 2008, 90, 369-383. [CrossRef] [PubMed]

35. Abraham, T.; Lewis, R.N.; Hodges, R.S.; McElhaney, R.N. Isothermal titration calorimetry studies of the binding of a rationally designed analogue of the antimicrobial peptide gramicidin s to phospholipid bilayer membranes. Biochemistry 2005, 44, 2103-2112. [CrossRef] [PubMed]

36. Sonnenfeld, E.M.; Beveridge, T.J.; Koch, A.L.; Doyle, R.J. Asymmetric distribution of charge on the cell wall of Bacillus subtilis. J. Bacteriol. 1985, 163, 1167-1171. [PubMed]

37. Alasino, R.V.; Ausar, S.F.; Bianco, I.D.; Castagna, L.F.; Contigiani, M.; Beltramo, D.M. Amphipathic and membrane-destabilizing properties of the cationic acrylate polymer Eudragit ${ }^{\circledR}$ E100. Macromol. Biosci. 2005, 5, 207-213. [CrossRef] [PubMed]

38. Romero, V.L.; Pons, P.; Bocco, J.L.; Manzo, R.H.; Alovero, F.L. Eudragit E100?? potentiates the bactericidal action of ofloxacin against fluoroquinolone-resistant Pseudomonas aeruginosa. FEMS Microbiol. Lett. 2012, 334, 102-110. [CrossRef] [PubMed]

39. Briuglia, M.L.; Rotella, C.; McFarlane, A.; Lamprou, D.A. Influence of cholesterol on liposome stability and on in vitro drug release. Drug Deliv. Transl. Res. 2015, 5, 231-242. [CrossRef] [PubMed]

40. Wilkinson, D.A.; Nagle, J.F. Metastability in the phase behavior of dimyristoylphosphatidylethanolamine bilayers. Biochemistry 1984, 23, 1538-1541. [CrossRef] 
41. Fauchere, J.; Pliska, V. Hydrophobic parameters \{pi\} of amino-acid side chains from the partitioning of N-acetyl-amino-acid amides. Eur. J. Med. Chem. 1983, 8, 369-375.

42. Eisenberg, D.; Weiss, R.M.; Terwilliger, T.C. The hydrophobic moment detects periodicity in protein hydrophobicity. Proc Natl Acad Sci USA 1984, 81, 140-144. [CrossRef]

43. Batcho, P.F.; Case, D.A.; Schlick, T. Optimized particle-mesh Ewald/multiple-time step integration for molecular dynamics simulations. J. Chem. Phys. 2001, 115, 4003-4018. [CrossRef]

44. Jorgensen, W.L.; Chandrasekhar, J.; Madura, J.D.; Impey, R.W.; Klein, M.L. Comparison of simple potential functions for simulating liquid water. J. Chem. Phys. 1983, 79, 926-935. [CrossRef]

45. Phillips, J.C.; Braun, R.; Wang, W.; Gumbart, J.; Tajkhorshid, E.; Villa, E.; Chipot, C.; Skeel, R.D.; Kalé, L.; Schulten, K. Scalable molecular dynamics with NAMD. J. Comput. Chem. 2005, 26, 1781-1802. [CrossRef] [PubMed]

46. Berry, J.D.; Neeson, M.J.; Dagastine, R.R.; Chan, D.Y.C.; Tabor, R.F. Measurement of surface and interfacial tension using pendant drop tensiometry. J. Colloid Interface Sci. 2015, 454, 226-237. [CrossRef] [PubMed]

47. Kahl, H.; Wadewitz, T.; Winkelmann, J. Surface tension of pure liquids and binary liquid mixtures. J. Chem. Eng. Data 2003, 48, 580-586. [CrossRef]

48. Arévalo, M.L.; Yarce, J.C.; Oñate-Garzón, J.; Salamanca, H.C. Decrease of Antimicrobial Resistance through Polyelectrolyte-Coated Nanoliposomes Loaded with $\beta$-Lactam Drug. Pharmaceuticals 2018, 12, 1. [CrossRef] [PubMed]

49. CLSI, M07-A10: Methods for Dilution Antimicrobial Susceptibility Tests for Bacteria That Grow Aerobically; Approved Standard-Tenth Edition., CLSI (Clinical Lab. Stand. Institute). (2015). [CrossRef]

50. Adetunji, V.O.; Adegoke, G.O. Formation of biofilm by strains of Listeria monocytogenes isolated from soft cheese 'wara' and its processing environment. J. Biotechnol. 2008, 7, 2893-2897.

(C) 2019 by the authors. Licensee MDPI, Basel, Switzerland. This article is an open access article distributed under the terms and conditions of the Creative Commons Attribution (CC BY) license (http:/ / creativecommons.org/licenses/by/4.0/). 